EESTI NSV TEADUSTE AKADEEMIA TOIMETISED, 27. KOIDE

KEEMIA, 1978, NR. 3

ИЗВЕСТИЯ АКАДЕМИИ НАУК ЭСТОНСКОЙ ССР. ТОМ 27

ХиМИЯ. 1978, № 3

удК 574.64

Анне ТАЛВАРИ, Х. ЯНКОВСКИИ

\title{
ОПРЕДЕЛЕНИЕ ХЛОРОРГАНИЧЕСКИХ ПЕСТИЦИДОВ И ПОЛИХЛОРБИФЕНИЛОВ В МОРСКИХ ОРГАНИЗМАХ
}

Anne TALVARI, H. JANKOVSKI. KLOORORGAANILISTE PESTITSIIDIDE JA POLUKLOORBIFENUULIDE MAÄRAMINE MEREORGANISMIDES

Anne TALVARI, H. YANKOVSKI. DETERMINATION OF CHLOROORGANIC PESTICIDES AND POLYCHLOROBIPHENYLS IN MARINE ORGANISMS

Хлорорганические пестициды (ХОП) и полихлорбифенилы (ПХБ) вещества, распространение которых в биосфере носит глобальный характер. Они обладают высокой химической и биохимической устойчивостью и способностью к биоаккумуляции и концентрации в пищевой цепи, поэтому требуется постоянный контроль за их уровнем в окружающей среде. Так как физико-химические (в частности, хроматографические) свойства соединений этих двух групп близки, они часто, с точки зрения аналитического определения, рассматриваются вместе.

Основным методом, применяемым при анализе ХОП и ПХБ, является газовая хроматография. Наличие в их молекуле атома хлора допускает использование детектора электронного захвата, что вполне соответствует требованию высокой чувствительности вследствие низких содержаний ХОП и ПХБ в природе. Реже применяются спектрофотометрические методы. Например, метод масс-спектрометрии, с помощью которого в 1966 г. С. Иенсену удалось идентифицировать ПХБ в виде неизвестных пиков на газохроматограммах экстрактов морских организмов ['], сейчас нашел применение при определении изомерного состава гомологов ПХБ $[2,3,4]$.

Трудности, возникающие при анализе ХОП и ПХБ, совместно присутствующих в пробе, связаны с неизбежным наложением их пиков на газохроматограммах, что в течение многих лет приводило к завышенным результатам при определении ХОП. Это обусловило поиски методов их раздельного определения. Были предложены методы химического модифицирования пробы (в том числе, хлорирование и гидрирование) [ ${ }^{5}$, а также предварительное разделение на группы с помощью колоночной хроматографии $\left[{ }^{6,7}\right]$. Однако до сих пор нет общепринятой стандартной методики определения ХОП в присутствии ПХБ.

Представляемая в данной работе методика определения ПХБ и ХОП при совместном их присутствии в пробе ткани рыб и бентоса заключается в экстракции измельченной ткани $\boldsymbol{H}$-гексаном, с последующей очисткой концентрированной $\mathrm{H}_{2} \mathrm{SO}_{4}$ и обработкой алкогольным раствором $\mathrm{KOH} \mathrm{с} \mathrm{целью} \mathrm{дегидрохлорирования} \mathrm{ДДТ} \mathrm{и} \mathrm{ДДД} \mathrm{в} \mathrm{ДДЕ.} \mathrm{Количествен-}$ ный анализ хлорорганических соединений проводится с помощью газовой хроматографии. 


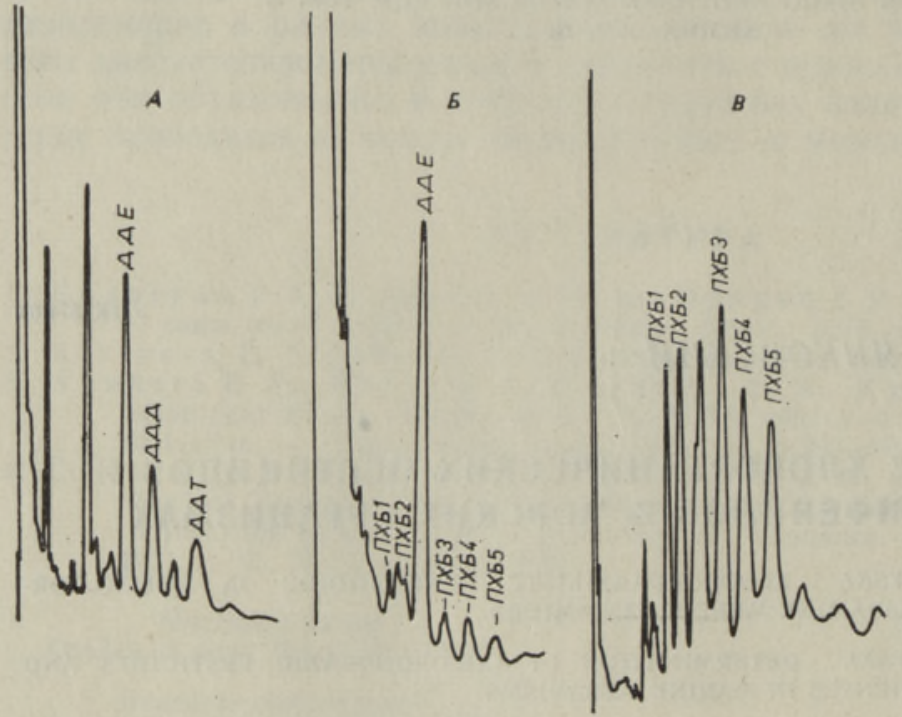

Газохроматограммы:

A - экстракта мышечной ткани салаки Балтийского моря, $\quad$ экстракта после обработки КОН, $B$ - стандартного раствора хлофена А50.

Навеска ткани (мышцы, печень и т. д.) в количестве $1-5$ г измельчается в фарфоровой ступке в присутствии безводного $\mathrm{Na}_{2} \mathrm{SO}_{4}$ или песка. Измельченная проба дважды экстрагируется н-гексаном. Аликвотная часть экстракта выпаривается досуха для определения жира. Экстракт очищается от липидов конщентрированной $\mathrm{H}_{2} \mathrm{SO}_{4}$. Очищенный экстракт выпаривается в вакуумно-ротационном испарителе почти досуха, и остаток растворяется в определенном объеме $н$-гексана (обычно 5 мл), после чего проба готова для газохроматографического анализа. Используется газовый хроматограф модель 3920 фирмы «Перкин-Эльмер» с детектором электронного захвата, радиоактивным источником которого является ${ }^{63 \mathrm{Ni}}$. В качестве газохроматографической колонки взята стеклянная трубка с внутренним диаметром 2 мм и длиной $2 м$. Неподвижной фазой служило силиконовое масло ДС-200, $5 \%$ от носителя (хромосорба Q), 80-100 меш. Температура испарителя $-210^{\circ}$, колонки $-190^{\circ}$, детектора $-250^{\circ}$. Газ-носитель - азот особой чистоты, скорость $55 \mathrm{~m} /$ мин. Газохроматограмма экстракта мышечной ткани салаки Балтийского моря представлена на рисунке $(A)$.

Для определения ПХБ проба обрабатывается равным объемом $10 \%$ ного раствора $\mathrm{KOH}$ в метаноле. В результате такой обработки изомеры ДДД и ДДТ дегидрохлорируются с образованием ДДЕ.

При количественной интерпретации хроматограмм используется метод внешней калибровки. $\gamma$-Изомер гексахлорциклогексана 'и пп'-ДДЕ определяются с исходной хроматограммы (рисунок, $A$ ). Содержание пп'-ДДД и пп'-ДДТ рассчитывается из разниц высот пиков на исходной хроматограмме и на хроматограмме экстракта после щелочной обработки (рисунок, Б).

ПХБ определяются сравниванием суммы высот пяти основных пиков (рисунок, 5 ) с суммой высот тех же пиков на хроматограмме стандартного вещества - хлофена А50 (рисунок, B). Результаты анализов искусственно составленных из исследуемых веществ смесей показали, что ошибка определения ПХБ по приведенной методике не превышает $20 \%$.

Представленная методика применяется для контроля уровня хлорорганических соединений в рыбах и бентосе Балтийского моря. 


\section{Л И Т Е Р А Т У Р А}

1. Jen s en, S. Report of a new chemical hazard. - New Scientist, 1970, v. 32, N 525, p. 6112.

2. Krupčik, J., Le clero, P., S̄imova, A., S uch a nek, P., Collak, M., Hriv$\mathrm{n}$ à $\mathrm{k}$, J. Possibilities and limitations of capillary gas chromatography and mass spectrometry in the analysis of polychlorobiphenyls. - J. Chromatogr., 1976, v. 119 , p. $271-283$.

3. Weil, L., Frimmel, F., Quentin, K.-E. Kombinierte Gas-Chromatographie/ Massenspektrometrie - eine hochempfindliche und spezifische Identifizierungsmethode. - Z. anal. Chem., 1974, Bd. 268, N 2, S. 97-101.

4. J a ns s on, B., Jensen, S., Olsson, M., Renberg, L., Sundström, G., $\mathrm{V}$ a z, R. Identification by gas chromatography - mass spectrometry of phenolic metabolites of PCB and pp'DDE isolated from Baltic guillemot and seal. Ambio, 1975, v. 4, N 2, p. $93-97$.

5. Beroza, M., Sarmiento, R. Apparatus for reaction gas chromatography instantenous hydrogenation on unsaturated esters, alcohols, ethers, ketones and other compound types and determination of their separation factors. - Analyt. Chem., 1966, v. 38 , p. $1042-1045$.

6. A r mour, J., B u rke, J. Method for separation polychlorinated biphenyls from DDT and its analogs. - J. Assoc. Offic. Anal. Chem., 1970, v. 53, N 4, p. 761-768.

7. Leoni, V. The separation of fifty pesticides and related compounds and polychlorobiphenyls into four groups by silicagel microcolumn chromatography. J. Chromatogr., 1971 , v. 62 , p. $63-71$.

\section{Институт термофизики и электрофизики} Академии наук Әстонской ССР

Поступила в редакцию 15/IX 1977 